\title{
Plasma Free Amino Acids in Normal Children and in Patients with Proteinocaloric Malnutrition: Fasting and Infection
}

\author{
J. GHISOlFI, P. CHARLET, N. SER, R. SALVAYRE, J. P. THOUVENOT, AND C. DUOLE \\ WITH THE TECHNICAL AID OF J. VAUX AND M. T. GIL \\ Pediatric A Medical Department (J.G., N.S., C.D., J.V., and M.T.G.), Medical Data Processing Laboratory (P.C.), \\ Biochemical Laboratory II (J.P.T.), and INSERM U-101, Biochimie des Lipides (R.S.), CHR Purpan, \\ Toulouse, France
}

\section{Summary}

This work attempts to perform a comparative study of plasma free amino acids in relation to nutritional situations. Children from 1-30 months of age were divided into five groups according to anamnestic, nutritional, clinical, and biologic data, as follows: group I, normal children; group II, normal children with extraenteral infection and correct oral feeding; group III, normal children with acute nonsevere diarrhea, perfused, and receiving either insufficient or no feeding; groups IV and V, children in a state of moderate or severe malnutrition, respectively (Table 1 ).

Results (Table 2) show that plasma amino acids are closely related to caloric and proteic feeding during the 2 or 3 days preceding blood samples, whatever the child's nutritional state. Feeding characteristics must be taken into account when studying plasma aminogram in malnutrition states. Infection and clinical enteropathy do not, however, disturb plasma amino acid levels to a large extent. Discrimination (Table 4) shows that the taurine decrease is the more important index in recognizing proteinocaloric malnutrition regardless of type of feeding. Other amino acid disturbances in particular branched chain amino acids are too closely related to feeding during the days preceding blood sampling to permit recognition of malnutrition. The formula, valine $+\mathbf{0 . 6 8}$ lysine, appears in our study to be the best linear index of the severity of malnutrition.

\section{Speculation}

Classic malnutrition indexes (amino acid sums and ratios) discriminate malnourished patients from simple fasting patients very poorly. Consequently, those indexes are not the best biologic means to identify malnutrition.

Numerous papers have been devoted to plasma amino acids in proteinocaloric malnutrition $(1,3,11,15,17,22,23,30,32)$. These works have not always shown concordant results and are sometimes difficult to analyze. The nutritional states in which studies are performed are not perfectly described. Patients' clinical or biologic states are not always specified. Various biochemical methods are used and there have been few statistical studies. Results are rarely compared to normal children examined under the same conditions. Furthermore, malnutrition is a complex pathologic state which combines in variable proportions insufficient feeding, infection, and enteropathy. Therefore, this study will try to specify plasma free amino acid deviations in proteinocaloric malnutrition relative to normal values and to determine the influence of fasting, infection, and enteropathy concerning plasma aminogram disorders.

\section{MATERIALS AND METHODS}

\section{PATIENT GROUPS}

This work concerns 149 children hospitalized in the pediatric department of CHR Purpan in Toulouse. The ages of these children vary between 1 and 30 months. We thought this large scattering of ages would not impede the study. The mean of ages among the different groups are not significantly different. The statistical study performed concerning these 149 children corroborates the absence of a relationship between age and amino acid values. These results agree with those of a previous study (10), which show that there is no significant relation between plasma levels of amino acids and age in children ranging in age from 1 month to 4 years in a normal nutritional and metabolic state.

The 149 children have been distributed into five groups, considering anamnestic, clinical, biologic, and nutritional data. No patient was in an acute metabolic state; in particular, there was no evidence of collapsus, blood sugar imbalance, or severe hydroelectrolytic disorder.

The five groups were comprised of three control groups of nutritionally normal children and two groups of children in a proteinocaloric malnutrition state. Group I (31 patients) was composed of normal children originating from normal pregnancies and of normal birthweight. At the time of examination they did not suffer from clinical or biologic conditions suggestive of an evolutive disease. They were in a good nutritional state and were correctly nourished orally according to their age and weight. Group II (30 patients) was composed of children in a normal nutritional state, nonperfused and correctly nourished, but suffering for more than 1 day and less than $\mathbf{4}$ days from an extraenteral, febrile, infectious disease: throat or ear affection, urinary or pulmonary infection, or meningitis. Group III (30 patients) gathered well nourished normal children with an acute diarrhea due to specific or nonspecific infection for more than 2 days and less than 4 days. These patients received orally or parenterally either no or very little feeding during the previous 2 days. For each patient receiving a glucosis perfusion, the perfusion rate was moderate and constant, not exceeding $0.25 \mathrm{~g} / \mathrm{kg} / \mathrm{hr}$. There was either no protein intake or less than $0.20 \mathrm{~g} / \mathrm{kg} / 24 \mathrm{hr}$, and no lipid intake as well. Each patient had a complementary hydroelectrolytic allowance. The two last groups are comprised of children in a proteinocaloric malnutrition state. We distinguished two categories of patients based on anamnestic, clinical, and biologic data. Group IV (30 patients) included children with proteinocaloric malnutrition of moderate severity. Twenty suffered from denutrition consecutive to severe chronic enteritis. As for the others, insufficient feeding was responsible for the malnutrition: anorexia, vomiting, 
dietary errors, or social problem. Twenty of these patients (13 enteritis) did not receive any perfusion during the weeks preceding blood sampling; 10 were being perfused when the samples were taken (glucosis rate less than $0.25 \mathrm{~g} / \mathrm{kg} / \mathrm{hr}$, no protide or lipid). Group V (28 patients) was composed of patients presenting severe states of proteinocaloric malnutrition. Fifteen children were suffering from severe diarrhea and the remaining 13 from very poor feeding over a period of several weeks (dietary errors, vomiting, or social problem); 16 of these patients were being perfused when the samples were taken (glucosis rate less than $0.25 \mathrm{~g} / \mathrm{kg} / \mathrm{hr}$, no protide or lipid). Biologic data showing the metabolic and nutritional state of each group are shown in Table 1.

\section{METHODS}

Blood Sampling. Venous blood was taken from each patient in the morning between 8 and $10 \mathrm{AM}$ after at least $12 \mathrm{hr}$ of fasting.

Sample Management. Blood taken on EDTA or dry heparin was centrifuged immediately. Proteins were then separated from plasma by $2.5 \%$ sulfosalicylic acid. The supernatant was either used immediately (36 serum samples) or stored in a freezer at $-20^{\circ}$ for $1-69$ days with a mean storage time of more than 5 days.

Analysis Techniques. Amino acids have been analyzed for each patient with a Technicon AutoAnalyzer (26-29). Separation was realized with a column $6 \mathrm{~mm}$ in diameter and $1.40 \mathrm{~m}$ in height containing a Chromobead type A resin. Elution was performed for $18 \mathrm{hr}$ with a $\mathrm{pH}$ gradient obtained by using three buffers of $\mathrm{pH} 2.8,3.8$, and 5.0, respectively; the temperature of the column was maintained at $35^{\circ}$ during the first $4 \mathrm{hr}$ (elution time of glutamine) and then at $56^{\circ}$ up to the end of elution. Development was performed at $95^{\circ}$ by using a ninhydrin-hydrindantin solution in nitrogen atmosphere.

Statistical Study. For each group and for each amino acid we have computed the mean value (expressed in micromoles per 100 $\mathrm{ml}$ ) and the corresponding 95\% confidence interval. With the aim of judging miscellaneous proteinocaloric malnutrition indexes which have been proposed $(1,3,15,22,23,30,32)$ we also determined for each group of patients the mean and $95 \%$ confidence interval of the sum of the 23 analyzed amino acids; the sum of essential amino acids (threonine, valine, methionine, isoleucine, leucine, phenylalanine, lysine, tryptophan); the sum of nonessential amino acids (14 others); the sum of branched chain amino acids; the ratios of the sum of nonessential to sum of essential amino acids, alanine to threonine, alanine to leucine, alanine to branched chain amino acids, phenylalanine to tyrosine, methionine to cysteine, glycine to valine, serine + glycine + alanine to branched chain amino acids, and the Whitehead ratio $=$ alanine + glycine + serine + glutamic acid + glutamine, to valine + leucine + isoleucine + phenylalanine + tyrosine + threonine + methionine.

Statistical study was performed in two steps. In the first step each variable was considered in an analytic way without taking into consideration relationships among variables. Mean comparisons among the five groups were performed by using variance analysis techniques. Each time a significant difference appeared in this global test (type 1 error less than 5\%), comparisons were performed between means considered two by two. Insofar as it was difficult to proceed by orthogonal hypothesis, we used a nonincreasing type 1 error method, the contrasts method (18). In the second step we tried to classify the patient by group through discrimination by amino acid values only. We looked for the amino acids and the relationships between them which allowed classification of a patient in a group with the lower risk of error. We used a stepwise discrimination program with a linear model (program Mahal 2 of IRIA (35)). Stepwise discrimination during the first step considers amino acids one by one and only the most discriminating amino acid is kept. During the following steps amino acids already chosen for their good discriminatory power are kept. The program then seeks among the remaining amino acids for the best one to add in order to improve classification. This program was applied to different groups of patients considered two by two in order to recognize the actual group of any patient by a dichotomy.

Two discriminations were performed. We first looked for amino acid levels most characteristic of malnutrition. For this we compared group III (nonmalnourished people with acute diarrhea and late fasting) to groups IV and V, together representing malnourished subjects. We can assume that if the variations in the level of some amino acids allow discrimination of malnourished people from group III patients, they also allow distinction of malnourished subjects from normals (group I) and infectious patients (group II). Secondly, we performed discrimination between group IV with moderate malnutrition and group $V$ with severe malnutrition. This last study identifies amino acids which permit the evaluation of the severity of malnutrition.

\section{RESULTS}

Relative to normal subjects (group I), proteinocaloric malnourished people (groups IV and V) are characterized by a significant decrease of most amino acids, excluding hydroxyproline, proline, glutamic acid, and alanine (Table 2). Glycine shows a tendency to increase, but this increase is not very marked. The severity of the malnutrition (group V) is paralleled by the importance of the amino acid disturbances. The amino acids which decrease most significantly in group V compared to group IV with moderate malnutrition are valine, isoleucine, leucine, lysine, and, among nonessential amino acids, tyrosine and ornithine.

Extraenteral infection has little effect on the aminogram. There are only slight differences between normal patients (group I) and infectious patients in a good nutritional state (group II). One can observe only a moderate but, nevertheless, significant decrease of threonine, tyrosine, tryptophan, and arginine.

Table 1. Mean values and their confidence intervals (confidence coefficient: 95\%) for biologic data defining nutritional and metabolic state in five groups of patients

Nutritional data

\begin{tabular}{lccccc} 
& $\begin{array}{c}\text { Group I } \\
(n=31)\end{array}$ & $\begin{array}{c}\text { Group II } \\
(n=30)\end{array}$ & $\begin{array}{c}\text { Group III } \\
(n=30)\end{array}$ & $\begin{array}{c}\text { Group IV } \\
(n=30)\end{array}$ & $\begin{array}{c}\text { Group V } \\
(n=28)\end{array}$ \\
\hline Relative wt (SD) & $-0.23 \pm 0.33$ & $-0.32 \pm 0.48$ & $-0.82 \pm 0.24$ & $-2.93 \pm 0.30$ & $-3.43 \pm 0.40$ \\
Relative size (SD) & $-0.2 \pm 0.4$ & $0.0 \pm 0.4$ & $-0.1 \pm 0.3$ & $-1.5 \pm 0.5$ & $-1.6 \pm 0.3$ \\
Protein (g/100 ml) & $6.65 \pm 0.14$ & $6.75 \pm 0.21$ & $6.31 \pm 0.16$ & $5.89 \pm 0.22$ & $4.97 \pm 0.20$ \\
Albumin (g/100 ml) & $3.83 \pm 0.16$ & $3.59 \pm 0.12$ & $3.63 \pm 0.14$ & $3.24 \pm 0.16$ & $2.48 \pm 0.16$ \\
Hemoglobin (g/100 ml) & $12 \pm 0.3$ & $10.8 \pm 0.4$ & $11.5 \pm 0.4$ & $11.3 \pm 0.4$ & $9.7 \pm 0.3$ \\
Potassium (mEq/100 & $0.48 \pm 0.02$ & $0.47 \pm 0.02$ & $0.48 \pm 0.02$ & $0.46 \pm 0.03$ & $0.38 \pm 0.03$ \\
$\quad$ ml) & $36 \pm 1$ & $34 \pm 2$ & $34 \pm 1$ & $35 \pm 2$ & $29 \pm 2$ \\
Hematocrit (\%) & $4.6 \pm 0.2$ & $4.5 \pm 0.2$ & $4.4 \pm 0.1$ & $4.0 \pm 0.2$ & $3.4 \pm 0.2$ \\
Red cells 106/mm & $139 \pm 0.9$ & $137 \pm 1.3$ & $137 \pm 1.1$ & $136 \pm 1.5$ & $137 \pm 1.5$ \\
Sodium (mEq/liter) & & & & &
\end{tabular}


Late fasting ( $48 \mathrm{hr}$ ) as observed in group III modifies considerably the plasma free amino acids. Compared to normal subjects (group I), group III children have a significant decrease of threonine, valine, leucine, isoleucine, tryptophan, citrulline, $\alpha$-aminobutyric acid, cysteine, tyrosine, histidine, and arginine. Amino acids values observed in group III are very close to those observed in group IV (group of moderate malnutrition). The only significant differences between groups III and IV concern methionine, taurine, and serine, which decrease. Differences between group III and group V (severe malnutrition) are considerably more important. Six essential amino acids (threonine, valine, methionine, isoleucine, leucine, and lysine) and six nonessential amino acids (taurine, serine, glutamine, tyrosine, ornithine, and arginine) decrease significantly.
For malnourished children (groups IV and V) we studied the influence of enteritis and of hydroelectrolytic perfusion on plasma amino acid variations. There was no significant variation either in group IV or in group V.

Malnutrition indexes (amino acids sums and ratios) were analyzed in each group (Table 3). All these indexes, except the methionine to cysteine ratio, varied significantly with severe malnutrition compared to groups I, II, and III. On the other hand, group IV with moderate malnutrition, even if different from group I of normal subjects, is not very different from group III with late fasting.

Stepwise discrimination (Table 4) demonstrates that the taurine decrease considered alone is sufficient in a large number of circumstances $(80.7 \%)$ to compare slightly or severely malnour-

Table 2. Mean values and their confidence interval (confidence coefficient: 95\%) of free plasma amino acids concentrations (micromoles per $100 \mathrm{ml}$ ) in five groups of patients ${ }^{1}$

\begin{tabular}{|c|c|c|c|c|c|}
\hline Amino acids & Group I & Group II & Group III & Group IV & Group V \\
\hline Taurine & $7.63 \pm 0.94$ & $7.21 \pm 0.67$ & $7.38 \pm 0.86$ & $3.74 \pm 0.57$ & $3.53 \pm 0.67$ \\
\hline OH-proline & $1.72 \pm 0.63$ & $1.54 \pm 0.48$ & $1.76 \pm 0.58$ & $1.71 \pm 0.57$ & $1.65 \pm 0.76$ \\
\hline Threonine & $10.77 \pm 1.04$ & $8.11 \pm 0.90$ & $8.41 \pm 0.84$ & $6.78 \pm 1.01$ & $5.45 \pm 1.05$ \\
\hline Serine & $13.66 \pm 1.18$ & $12.89 \pm 1.06$ & $16.02 \pm 2.27$ & $12.39 \pm 1.32$ & $10.19 \pm 1.57$ \\
\hline Glutamine & $68.13 \pm 5.36$ & $60.57 \pm 4.90$ & $66.06 \pm 5.92$ & $53.43 \pm 5.77$ & $42.44 \pm 6.47$ \\
\hline Proline & $17.79 \pm 1.64$ & $14.41 \pm 1.55$ & $17.65 \pm 2.69$ & $19.59 \pm 2.53$ & $16.45 \pm 3.36$ \\
\hline Glutamic acid & $9.82 \pm 0.94$ & $9.84 \pm 1.30$ & $11.69 \pm 1.84$ & $11.85 \pm 1.65$ & $9.32 \pm 2.02$ \\
\hline Citrulline & $2.40 \pm 0.39$ & $1.94 \pm 0.39$ & $1.05 \pm 0.27$ & $1.08 \pm 0.35$ & $0.88 \pm 0.24$ \\
\hline Glycine & $21.03 \pm 1.82$ & $19.78 \pm 1.87$ & $27.37 \pm 3.19$ & $23.28 \pm 2.77$ & $24.88 \pm 4.27$ \\
\hline Alanine & $26.35 \pm 2.38$ & $23.40 \pm 2.40$ & $23.45 \pm 2.64$ & $25.25 \pm 3.32$ & $24.38 \pm 5.12$ \\
\hline$\alpha$-Amino butyric acid & $1.74 \pm 0.18$ & $1.45 \pm 0.21$ & $0.88 \pm 0.13$ & $1.04 \pm 0.19$ & $0.70 \pm 0.18$ \\
\hline Valine & $19.30 \pm 1.25$ & $17.76 \pm 1.25$ & $10.97 \pm 0.89$ & $11.38 \pm 1.15$ & $7.19 \pm 0.90$ \\
\hline Cysteine & $8.10 \pm 0.84$ & $7.20 \pm 0.50$ & $5.19 \pm 0.64$ & $5.12 \pm 0.86$ & $4.21 \pm 0.99$ \\
\hline Methionine & $2.07 \pm 0.21$ & $1.91 \pm 0.15$ & $1.88 \pm 0.22$ & $1.44 \pm 0.15$ & $1.25 \pm 0.22$ \\
\hline Isoleucine & $5.18 \pm 0.34$ & $5.20 \pm 0.53$ & $3.48 \pm 0.39$ & $3.31 \pm 0.40$ & $2.07 \pm 0.40$ \\
\hline Leucine & $9.80 \pm 0.67$ & $9.58 \pm 0.69$ & $6.44 \pm 0.60$ & $6.65 \pm 0.73$ & $4.44 \pm 0.89$ \\
\hline Tyrosine & $6.17 \pm 0.46$ & $4.70 \pm 0.44$ & $3.73 \pm 0.44$ & $3.46 \pm 0.45$ & $2.24 \pm 0.39$ \\
\hline Phenylalanine & $5.13 \pm 0.41$ & $5.12 \pm 0.52$ & $4.62 \pm 0.57$ & $4.05 \pm 0.59$ & $3.58 \pm 0.59$ \\
\hline Ornithine & $4.90 \pm 0.45$ & $5.45 \pm 0.54$ & $4.47 \pm 0.52$ & $4.51 \pm 0.66$ & $3.08 \pm 0.65$ \\
\hline Lysine & $15.04 \pm 0.99$ & $13.33 \pm 1.18$ & $12.39 \pm 1.32$ & $11.35 \pm 1.39$ & $6.86 \pm 0.99$ \\
\hline Histidine & $7.98 \pm 0.48$ & $7.21 \pm 0.58$ & $5.88 \pm 0.57$ & $6.24 \pm 0.80$ & $5.15 \pm 0.91$ \\
\hline Tryptophan & $3.69 \pm 0.36$ & $2.87 \pm 0.29$ & $1.81 \pm 0.41$ & $1.80 \pm 0.33$ & $1.05 \pm 0.35$ \\
\hline Arginine & $6.84 \pm 0.54$ & $5.40 \pm 0.49$ & $4.68 \pm 0.56$ & $3.99 \pm 0.50$ & $2.83 \pm 0.60$ \\
\hline
\end{tabular}

${ }^{1}$ Group I, normal control subjects; group II, control infected patients on normal diet; group III, children presenting acute benign diarrhea in the state of proteinocaloric fasting; group IV, moderate malnutrition; group V, severe malnutrition.

Table 3. Sums and ratio of plasma amino acids $(A A)$ levels expressed in micromoles per $100 \mathrm{ml}$ for each group

\begin{tabular}{|c|c|c|c|c|c|}
\hline Malnutrition index & Group I & Group II & Group III & Group IV & Group V \\
\hline All amino acids sum & $263.07 \pm 12.91$ & $236.30 \pm 13.39$ & $234.69 \pm 17.49$ & $212.23 \pm 15.66$ & $172.90 \pm 21.63$ \\
\hline $\begin{array}{l}\text { Essential amino acids } \\
\text { sum }\end{array}$ & $66.92 \pm 3.42$ & $60.82 \pm 3.43$ & $46.82 \pm 3.51$ & $44.19 \pm 3.86$ & $29.84 \pm 3.55$ \\
\hline Nonessential AA sum & $196.15 \pm 10.59$ & $175.48 \pm 11.19$ & $187.87 \pm 15.34$ & $168.04 \pm 13.51$ & $143.06 \pm 19.34$ \\
\hline Branched chain AA sum & $34.28 \pm 2.03$ & $32.54 \pm 2.25$ & $20.89 \pm 1.77$ & $21.34 \pm 2.13$ & $13.70 \pm 1.97$ \\
\hline $\begin{array}{l}\text { Nonessential to essential } \\
\text { amino acids ratio }\end{array}$ & $2.95 \pm 0.14$ & $2.91 \pm 0.17$ & $4.07 \pm 0.27$ & $3.94 \pm 0.36$ & $4.91 \pm 0.54$ \\
\hline Whitehead's ratio & $2.43 \pm 0.17$ & $2.45 \pm 0.19$ & $3.77 \pm 0.31$ & $3.63 \pm 0.49$ & $4.39 \pm 0.57$ \\
\hline $\begin{array}{l}\text { Alanine to threonine ra- } \\
\text { tio }\end{array}$ & $3.66 \pm 0.38$ & $4.32 \pm 0.48$ & $4.26 \pm 0.59$ & $6.30 \pm 1.60$ & $6.90 \pm 1.59$ \\
\hline Alanine to leucine ratio & $2.47 \pm 0.27$ & $2.22 \pm 0.24$ & $3.43 \pm 0.49$ & $3.66 \pm 0.62$ & $5.86 \pm 1.38$ \\
\hline $\begin{array}{l}\text { Alanine to branched } \\
\text { chain amino acids ra- } \\
\text { tio }\end{array}$ & $0.70 \pm 0.07$ & $0.66 \pm 0.08$ & $1.05 \pm 0.14$ & $1.12 \pm 0.18$ & $1.72 \pm 0.36$ \\
\hline $\begin{array}{l}\text { Phenylalanine to tyro- } \\
\text { sine ratio }\end{array}$ & $0.85 \pm 0.07$ & $1.17 \pm 0.17$ & $1.37 \pm 0.25$ & $1.21 \pm 0.13$ & $1.8 \pm 0.29$ \\
\hline $\begin{array}{l}\text { Methionine to cysteine } \\
\text { ratio }\end{array}$ & $0.29 \pm 0.05$ & $0.27 \pm 0.02$ & $0.39 \pm 0.05$ & $0.33 \pm 0.06$ & $0.40 \pm 0.09$ \\
\hline Glycine to valine ratio & $0.84 \pm 0.09$ & $0.87 \pm 0.10$ & $1.93 \pm 0.23$ & $1.65 \pm 0.27$ & $2.79 \pm 0.56$ \\
\hline $\begin{array}{l}\text { Serine }+ \text { glycine }+ \text { ala- } \\
\text { nine to branched } \\
\text { chain ratio }\end{array}$ & $1.58 \pm 0.14$ & $1.54 \pm 0.14$ & $2.85 \pm 0.30$ & $2.61 \pm 0.38$ & $4.06 \pm 0.71$ \\
\hline
\end{tabular}


Table 4. Analysis of stepwise discrimination

\begin{tabular}{|c|c|c|c|}
\hline Discrimination step & Discriminating linear functions & Threshold $\mu \mathrm{mol} / 100^{\circ} \mathrm{ml}$ & Well classified patients, \% \\
\hline \multicolumn{4}{|c|}{$\begin{array}{l}\text { Discrimination between group III and } \\
\text { groups IV and } V^{1}\end{array}$} \\
\hline Step 1 & Taurine & 4.9 & 80.7 \\
\hline Step 3 & Taurine +0.01 glutamine -0.09 proline & 6.0 & 81.4 \\
\hline \multicolumn{4}{|c|}{ Discrimination between groups IV and $\mathrm{V}^{2}$} \\
\hline Step 1 & Valine & 9.1 & 77.6 \\
\hline
\end{tabular}

${ }^{1}$ This analysis discriminates among several amino acids to indicate the one most characteristic of proteinocaloric malnutrition for the patients of group III (normal control subjects presenting with acute diarrhea and in a recent state of proteinocaloric fasting) and for all of the malnourished patients of group IV (moderate malnutrition) and group V (severe malnutrition).

${ }^{2}$ This analysis indicates the amino acids most characteristic of severe proteinocaloric malnutrition for the children of group IV (moderate proteinocaloric malnutrition) and for patients of group $\mathrm{V}$ (severe malnutrition).

Table 5. Discriminating value classic malnutrition indexes ${ }^{1}$

\begin{tabular}{|c|c|c|c|c|}
\hline Test used in discriminating & \multicolumn{2}{|c|}{ Group III and groups IV, V } & \multicolumn{2}{|c|}{ Group IV and group V } \\
\hline All AA sum & 64 & $>225.7$ & 63 & $>203.6$ \\
\hline Nonessential AA sum & 58 & $>181.0$ & 52 & $>164.3$ \\
\hline Branched chain AA sum & 61 & $>19.3$ & 72 & $>17.6$ \\
\hline Nonessential/essential ratio & 56 & $<4.2$ & 69 & $<4.4$ \\
\hline Alanine/leucine ratio & 50 & $<4.6$ & 67 & $<5.4$ \\
\hline Alanine/branched chain AA ratio & 56 & $<1.4$ & 66 & $<1.6$ \\
\hline Phenylalanine/tryosine ratio & 52 & $<1.4$ & 67 & $<1.5$ \\
\hline Methionine/cysteine ratio & 52 & $>0.4$ & 40 & $>0.4$ \\
\hline Glycine/valine ratio & 50 & $<2.8$ & 66 & $<3.0$ \\
\hline $\begin{array}{l}\text { Serine }+ \text { glycine }+ \text { alanine/ } \\
\text { branched chain AA ratio }\end{array}$ & 47 & $<3.6$ & 72 & $<3.9$ \\
\hline
\end{tabular}

${ }^{1}$ Discrimination thresholds are expressed in micromoles per $100 \mathrm{ml}$. Signs $>$ or < indicate a patient is to be considered as belonging to group III in the first case and group IV in the second case if the corresponding test is respectively greater or smaller than threshold. AA: amino acid.

ished children to normal control children, even when they have been in a fasting state for a few days. Variations in the other amino acids do not actually improve the results that are shown with taurine in differentiating malnourished children from nonmalnourished ones. The best linear formula combining two amino acids is taurine +0.05 glutamine (the coefficient 0.05 attributed to glutamine is given by the computer program). This formula permits the best classification of patients between a group of malnourished children and a group of nonmalnourished children when using two amino acids. The best three amino acids formula (step 3 ) introduces proline as the third amino acid. In this formula, coefficients are 1 for taurine, 0.01 for glutamine, and 0.09 for proline. Classification is not appreciably better than with taurine alone. Without considering sample fluctuations, stepwise discrimination principle implies that the increase found from one step to the next by adding new amino acids becomes less and less. We can conclude that taurine is sufficient in the aminogram to predict malnutrition with the least error. If we do not take into account taurine, and exclude it from the discrimination analysis, the next best one appears to be methionine. However, its discriminating power is obviously poorer ( $68.3 \%$ correctly classified subjects).

Discrimination between groups IV and V was performed to look for amino acids which determine the severity of malnutrition. It showed that the decrease of both valine and lysine was the best index ( $81 \%$ of correctly classified subjects). Decrease of other amino acids, although noticeable, does not improve discrimination.

On the other hand we studied the discriminating value of classic malnutrition indexes applied to our data (Table 5). The best one appeared to be the sum of essential amino acids with only $67.05 \%$ of correctly classified subjects. The sum of all the amino acids and the sum of branched chain amino acids have a lower discriminating power (63.6 and $61 \%)$.

Amino acid ratios seem to be poorly discriminating. The most reliable in our study was the alanine to threonine ratio $(63.6 \%)$.

\section{DISCUSSION}

\section{GROUPS OF PATIENTS}

The statistical study of the nutritional data (Table 1) illustrates differences between the clinical groups relative to the children's nutritional state. There is no statistical difference in the sodium levels among the five groups. This suggests that patient hydration is correct in each group. Relative weight and size are significantly less among groups IV and V by comparison with groups I, II, and III. There is no significant difference between these two groups of malnourished children although the severity of their denutrition state is different as shown by biologic tests. No significant difference can be observed between groups I and II of normal subjects. Group III with acute diarrhea and recent fasting is in most cases not different from groups I and II, except when considering the total protein level, which is significantly less. Serum albumin level and red cell count of group IV comprised of moderately malnourished children are lower than those of groups I, II, and III. The total protein level of group IV is lower than in groups I and II but is not significantly different from group III. Group IV is not different from normal subjects when considering hemoglobin, hematocrit, and potassium. 
The biologic data are significantly different among severely malnourished children of group V. Each test is significantly lower, with the exception of the sodium levels. The fact that group $\mathrm{V}$ is the only group where hematocrit, hemoglobin, and potassium are decreased should be emphasized. The serum albumin level $(2.48$ $\pm 0.16 \mathrm{~g} / 100 \mathrm{ml}$ ) suggests the importance of malnutrition also.

The group of children in a proteinocaloric fasting state (group III) has to be discussed. For obvious moral reasons, we were obliged to take patients who, because of their disease (nonsevere acute diarrhea), had no or insufficient oral feeding in order to get nonmalnourished normal patients in a fasting state. Other than fasting, two factors can disturb plasma amino acids levels among these children: diarrhea by itself and hydroelectrolytic perfusion. If, during diarrhea, there is an increase of amino acid spoilage by feces, it becomes substantial in severe and refractory diarrhea (9). Group III patients never suffered from severe diarrhea. However, Isoun et al. (16) showed that among animals suffering for 4-6 days with infectious diarrhea, an enteral virus infection was able to decrease essential amino acid levels and increase glycine, alanine, and serine levels. They emphasize that the essential amino acid decrease is particularly important when a hypoprotidic diet is given to the animal. Feigin et al. (8) report plasma amino acid decrease among patients suffering from typhoid. They believe that both infection and enteral spoilage are responsible for the disturbances. Thus, group III patients cannot be considered only as normal patients in a fasting state for $48 \mathrm{hr}$. Nevertheless, they comprise in our study a comparative group insofar as these normal children in a good nutritional state suffer from important disorders: acute diarrhea and insufficient feeding often present during malnutrition. The influence of glucosis perfusion on plasma aminogram among all group III patients has also to be discussed. The influence of a glucosis perfusion upon free amino acids is known from experimental works. Eskeland et al. (7) and De Barnola et al. (5), using animals, show that an intravenous glucosis isoenergetic perfusion results in a decrease of valine, isoleucine, leucine, phenylalanine, and, to a smaller extent, lysine and methionine, and in an increase of alanine. Grimble et al. (13) in studies with children and Swenseid et al. (27) with adults report that oral glucosis administration results in the decrease of most plasma free amino acids. It is important to note that in these two last works a heavy glucosis absorption was referred to, which involved an insulin secretion responsible for the amino acid disturbances. However, Marliss and Aoki (19) proved that glucosis administered iv at a very low constant rate $(120 \mathrm{~g} / 24 \mathrm{hr})$ to obese adult patients in a fasting state for 5 weeks is sufficient to induce insulin increase and consequently a significant decrease of threonine, valine, isoleucine, leucine, phenylalanine, lysine, serine, proline, glycine, alanine, $\alpha$-amino-butyric acid, tyrosine, ornithine, and histidine. In our study, the metabolic state is quite different. Group III patients did not receive a large amount of glucosis (glucosis constant rate less than $0.25 \mathrm{~g} / \mathrm{kg} /$ day) and they were not in a prolonged fasting state (less than 3 days). Furthermore, we have verified that among the 58 malnourished children there is no significant difference in plasma aminograms between patients with glucosis perfusion and patients without glucosis perfusion.

Patients of groups IV and $V$ were in a proteinocaloric malnutrition state different from malnutrition as defined in numerous papers $(1,3,11,15-17,22,23,30,32)$. In most cases, indeed, malnourished patients belong to populations of developing countries where the nutritional factor is prevalent. In most of our observations, malnutrition is consecutive to enteropathy $(35 / 58)$. But all these patients suffer of a malnutrition known as marasmus.

\section{METHODOLOGY}

We need not discuss daily amino acids fluctuations since sampling was always performed between 8 and 10 AM. However, some of our samples were stored in a freezer for a variable period longer than 1 month. Dickinson et al. (6) and Armstrong and Save (2) reported that storage at $-15^{\circ}$ for more than 3 days results in glutamine decrease and glutamic acid increase. These conclusions are not corroborated by Rosemblum (20). For this study we have calculated correlation coefficients between storage duration and glutamic acid levels and between storage duration and glutamine levels. We found no significant relation between these amino acids levels and storage duration in any of the five groups.

\section{RESULTS}

Plasma free amino acids among malnourished children have been studied by numerous authors, namely Arroyave et al. (3), Holt et al. (15), Vis (31) in 1963, and Truswell et al. (30) in 1966. They defined specific variations in plasma amino acids relative to such metabolic situations. The conclusions of these studies are not always in agreement. Disparity of results may be due to diversity in analysis methods and to method of selection of malnourished patients. Singh et al. (23) and Vis (32) believe that a plasma aminogram model specific for kwashiorkor may be individualized, whereas aminogram would be normal in marasmus. This is not corroborated by every author. Anasuya and Rao (1) and Saunders et al. (22) report in marasmus plasma amino acid disturbances similar to those of kwashiorkor. In experimental works, Grimble and Whitehead (12), Kumar et al. (17), and Salem et al. (21) find the same disturbances in relation to global proteinocaloric malnutrition. Nutritional circumstances leading our patients to global malnutrition explain amino acid decreases in our study. However, they raise the problem of the normality of aminogram in marasmus.

These biologic disturbances have to be interpreted in relation to feeding. Plasma aminogram indeed is related to proteic and caloric absorption during the 2 or 3 days preceding blood sampling; Snyderman et al. (24, 25), Azar et al. (4), Weller et al. (34), Holmgren et al. (14), Swenseid et al. (28), and Grimble and Whitehead (11) demonstrated that some of the variations in plasma amino acid in the case of early proteinocaloric malnutrition were due to the lack of protein in feeding rather than to the metabolic disorders specific for these states. Our results draw the same conclusion. If severe malnutrition can be distinguished clearly in every nutritional situation, there are only slight differences between group III patients with enteric infection and late fasting and group IV patients with moderate malnutrition.

The influence of infection is less. Group II, comprised of patients with extraenteral infection who were in a good nutritional state, is not very different from group I, comprised of normal subjects. Only a slight but nevertheless significant decrease of threonine, tryptophan, tyrosine, and arginine can be noted. However, most amino acid levels decrease greatly in malnutrition states.

Clinically evident enteropathy in our cases of proteinocaloric malnutrition, is not reflected in the aminogram. Comparisons is performed in group IV with moderate malnutrition and in group $V$ with severe malnutrition do not exhibit any significant difference between children with chronic diarrhea and children without diarrhea.

In view of our results, the value of malnutrition indexes currently proposed in the literature (Table 5 ) requires closer scrutiny. The sum of all plasma free amino acids, sum of essential amino acids, sum of nonessential amino acids, and sum of branched chain amino acids do not allow differentiation of a simple fasting state from moderate malnutrition. Yet they decrease in a very significant way with severe malnutrition. The same can be said of the amino acid ratios, except for the Whitehead and methionine to cysteine ratios which are not disturbed by malnutrition, even if severe, compared to a simple fasting state. It should be noted that, as Wennemacher et al. (33) observed, we found an increase in the phenylalanine to tyrosine ratio among group II and group III children. In our study this increase is significant with group III only. Consequently, this ratio can not be considered as a satisfactory index of malnutrition.

Discrimination helps us in interpreting the aminogram. It shows that the whole aminogram is far from necessary in differentiating malnutrition from fasting or to distinguish in malnourished sub- 
jects the severity levels we have established. It appears that: 1) if the taurine rate is less than $4.9 \mu \mathrm{mol} / 100 \mathrm{ml}$, malnutrition is probable; 2 ) if the formula valine +0.68 lysine is less than 15.6 $\mu \mathrm{mol} / 100 \mathrm{ml}$ malnutrition is very likely severe.

Since the methionine discriminating power comes just after that of taurine, we can wonder why methionine is not taken into account in this rule. This result of discrimination analysis is very probably due to the fact that information brought by methionine in discriminating malnutrition from fasting is already involved in the information brought by taurine.

On the other hand, it should be noted that amino acids which lead to the best discrimination between normal and malnourished subjects (branched chain amino acids) can not actually be used insofar as these amino acids decrease during fasting.

We would like to emphasize that the classic indexes of malnutrition discriminate very poorly between malnutrition and fasting states. Since fasting often exists in malnourished populations, these classic indexes are thus unlikely to be the best biologic means of recognizing a moderate malnutrition state. In the event of severe malnutrition any amino acid decrease is sufficiently discriminatory for diagnosis.

\section{REFERENCES AND NOTES}

1. Anasuya, A., and Rao, B. S.: Plasma aminoacid pattern in kwashiorkor and marasmus. Amer. J. Clin. Nutr., 21: 723 (1968).

2. Armstrong, M. D., and Stave, U.: A study of plasma free aminoacid levels: Study of factors affecting validity of aminoacids analyses. Metabolism, 22: 549 (1973).

3. Arroyave, G., Wilson, D., De Funes, C., and Behar, M.: The free aminoacids in blood plasma of children with kwashiorkor and marasmus. Amer. J. Clin. Nutr., I1: 517 (1962).

4. Azar, M., Ter-Sarkissian, N., Barendi, M., Medayat, H., and Donoso, G.: Effect of fasting and of a protein free diet on aminoacid ratios in plasma and erythrocytes in rats. Acta Paediat. Scand., 62: 655 (1973).

5. De Barnola, F. V.: The effect of insulin on plasma free aminoacids. Acta Physiol. Lat. Amer., 15: 260 (1965).

6. Dickinson, J. C., Rosemblum, H., and Hamilton, P. B.: Ion exchange chromatography of the free aminoacids in the plasma of the newborn infant. Pediatrics, 36: 2 (1965).

7. Eskeland, B. P., Fander, W. H., and Preston, R. L.: Intravenous energy infusion in lambs: Effects on nitrogen retention, plasma free aminoacids and plasma urea nitrogen. Brit. J. Nutr., 31: 201 (1974).

8. Feigin. R. D., Klainer, A. S., Beisel, W. A., and Hornick, B. B.: Whole blood aminoacids in experimentally induced typhoid fever in man. N. Engl. J. Med., 278: 293 (1968).

9. Ghadimi, H., Kumar, S., and Abachi, F.: Endogenous aminoacid loss and its significance in infantile diarrhea. Pediat. Res., 7: 161 (1973).

10. Ghisolfi, J., Augier, D., Regnier, C., and Dalous, A.: Etude des variations physiologiques en fonction de l'àge du taux des acides aminés libres plasmatiques chez l'enfant normal. Arch. Franç. Pediat., 30: 951 (1973).

11. Grimble, R. F., and Whitehead, R. G.: Fasting serum aminoacid patterns in kwashiorkor and after administration of different levels of protein. Lancet, $i$. 918, (1970).

12. Grimble, R. F., and Whitehead, R. G.: Changes in the concentration of specific aminoacids in the serum of experimentally malnourished pigs. Brit. J. Nutr., 24: 557 (1970).

13. Grimble, R. F., and Whitehead, R. G.: The effect of an oral glucose load on serum free aminoacid concentration in children before and after treatment for kwashiorkor. Brit. J. Nutr., 25: 253 (1971).

14. Holmgren, G.: Effect of low, normal, and high dietary protein intake on urinary aminoacid excretion and plasma aminogram in children. Nutr. Metabol., 16: 223 (1974).

15. Holt, L. E., Snyderman, S. E., Norton, P. M., Roitman, E., and Finch, J.: The plasma aminogram in kwashiorkor. Lancet, ii: 1343 (1963).

16. Isoun, T., Whitehair, C., and Bergen, W.: Influence of a viral enteric infection on the aminogram and pathology of protein calorie malnutrition in the pig. Amer. J. Clin. Nutr., 26: 835 (1973).

17. Kumar, V., Chase, M. P., Hammond, K., and O'Brien, D.: Alterations in blood biochemical tests in progressive protein malnutrition. Pediatrics, 49: 736 (1972).

18. Lellough, J., and Lazar, P.: Méthodes statistiques en expérimentation biologique, p. 132 (Editions Médicales Flammarion, Paris, 1974).

19. Marliss, E. B., Aoki, T. T., and Lahill, J. F.: Insulin and aminoacid métabolism in prolonged fasted man. Diabetologia, 6: 639 (1970).

20. Rosemblum, R.: Stability of glutamine in vitro. Proc Soc. Exp. Biol. Med., 119: 763 (1965).

21. Salem, S. 1., Hegazı, S. M., and Moruos, S. K.: Expenmental protein energy deficiency in rats: Ratio of serine + glycine to threonine as an index of deficiency. Brit. J. Nutr., 29: 113 (1973).

22. Saunders, S. J., Truswell, A. S., Barbezat, G. O., Wittman, W., and Hansen, J. D. L.: Plasma free aminoacid pattern in protein calorie malnutrition. Lancet, $i$ : 795 (1967).

23. Singh, P. I., Subhash, C. S., and Saini, A. S.: Plasma non essential to essential aminoacid ratio in marasmus. Amer. J. Clin. Nutr., 26: 484 (1973).

24. Snyderman, S. E., Holt, L. E., Morton, P. M., and Phansalkar, S. V.: Influence of protein intake on free aminoacid content of plasma and red blood cells. Amer. J. Clin. Nutr., 23: 890 (1970).

25. Snyderman, S. E., Holt, L. E., Norton, P. M., Roitman, E. L., and Phansalkar, S. V.: The plasma aminogram: Influence of the level of protein intake and a comparison of whole protein and aminoacid diets. Pediat. Res., 2: 131 (1968).

26. Spackman, D. H., Stein, W. H., and Moore, S.: Automatic recording apparatus for use in the chromatography of amino acids. Anal. Chem., 30(7): 1190 (1958).

27. Swendseid, M. G., Tuttle, S. G., Drenick, E. J , Joren, C. B., and Massey, F. T.: Plasma aminoacid response to glucose administration in various nutritive states. Amer. J. Clin. Nutr., 20: 243 (1967)

28. Swendseid, M. E., Yamada, E. C., Vinyard, E., and Figueroa, W. C.: Plasma aminoacid levels in young subjects receiving diets containing 14 or 3-5 g nitrogen per day. Amer. J. Clin. Nutr., 21: 1381 (1968).

29. Techniques in Amino Acids Analysis (Technicon Instruments Co., Tarrytown, NY, 1966).

30. Truswell, A. S., Wannenburg, P., Wittman, W., and Mansen, J. P.: Plasma aminoacids in kwashiorkor. Lancet, $i$ : 1162 (1966).

31. Vis, H. L.: Aspects et mécanismes des hyperaminoaciduries de l'enfance. In: Recherches sur le Kwashiorkor, le rachitisme commun, le scorbut (Arscia S.A., Maloine, Paris, 1973).

32. Vis, H. L.: Acides aminés et kwashiorkor. XXIVème congrès d'association des pédiatres de langue française, Vol. II, p. 219 (Expansion Scientifique Française, Paris, 1975).

33. Wannemacher, R. W., Klainer, A. S., Dinterman, R. E., and Beisel, W. R.: The significance and mechanism of an increased serum phenylalanine-tyrosine ratio during infection. Amer. J. Clin. Nutr., 29: 997 (1976).

34. Weller, L A., Margen, S., and Calloway, D. M.: Variation in fasting and postprandial aminoacids of men fed adequate or protein free diets. Amer. J. Clin. Nutr., 22: 1577 (1969).

35. Instistut de Recherches en Informatique et an Automatique, Rocquencourt, France.

36. Requests for reprints should be addressed to: Dr. J. Ghisolfi, Clinique Medicale Infantile A, CHR Purpan, 31052 Toulouse Cedex (France).

37. Received for publication July 8, 1977.

38. Accepted for publication November 16, 1977. 